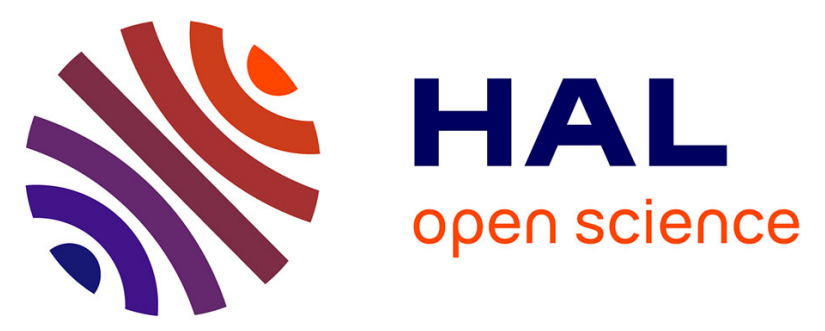

\title{
Does interindividual variability of saliva affect the release and metabolisation of aroma compounds ex-vivo? The particular case of elderly suffering or not from hyposalivation
}

Carolina Muñoz González, Marine Brulé, Gilles Feron, Francis Canon

\section{To cite this version:}

Carolina Muñoz González, Marine Brulé, Gilles Feron, Francis Canon. Does interindividual variability of saliva affect the release and metabolisation of aroma compounds ex-vivo? The particular case of elderly suffering or not from hyposalivation. Journal of Texture Studies, 2019, 50 (1), pp.36-44. 10.1111/jtxs.12382 . hal-02626519

\section{HAL Id: hal-02626519 \\ https://hal.inrae.fr/hal-02626519}

Submitted on 26 May 2020

HAL is a multi-disciplinary open access archive for the deposit and dissemination of scientific research documents, whether they are published or not. The documents may come from teaching and research institutions in France or abroad, or from public or private research centers.
L'archive ouverte pluridisciplinaire HAL, est destinée au dépôt et à la diffusion de documents scientifiques de niveau recherche, publiés ou non, émanant des établissements d'enseignement et de recherche français ou étrangers, des laboratoires publics ou privés. 
Does interindividual variability of saliva affect the release and metabolisation of aroma compounds ex-vivo? The particular case of elderly suffering or not from hyposalivation

Running title: Aroma-saliva interactions in the elderly

\section{Authors:}

C. Muñoz-González*, M. Brulé, G. Feron, F. Canon

*Corresponding author: carolina.munoz@inra.fr

\section{Affiliation:}

Centre des Sciences du Goût et de l'Alimentation, UMR1324 INRA, UMR6265 CNRS

Université de Bourgogne, Agrosup Dijon, F-21000 Dijon, France

This article has been accepted for publication and undergone full peer review but has not been through the copyediting, typesetting, pagination and proofreading process, which may lead to differences between this version and the Version of Record. Please cite this article as doi: $10.1111 /$ jtxs. 12382 
Abstract

The aim of this work was to study the effects of interindividual variability of human elderly saliva on aroma release and metabolisation by ex vivo approaches. Thirty individuals suffering or not from hyposalivation were selected from a panel formed by 110 elderly people (aged $>65$ years old) that were matched by age and sex. Then, their stimulated saliva samples were independently incubated in presence of three aroma compounds (ethyl hexanoate, octanal, 2-nonanone) to perform headspace-gas chromatography (HS-GC) and liquid/liquid extraction-gas chromatography mass spectrometry (LLE-GC/MS) analyses. These assays revealed that the extent of saliva effect on the release and metabolisation of aroma compounds was highly dependent on the chemical family of the compounds (octanal>ethyl hexanoate>2nonanone). Moreover, salivas from the hyposalivator (HPS) group exerted a significant lower release and/or higher metabolisation than those of the control group for the three assayed compounds. Regarding the biochemical characterization of the saliva samples, no significant differences were found in the total protein content between the two groups. This does not preclude the involvement of specific proteins on the observed results that need to be clarified in further experiments. Saliva from the HPS group presented a significantly higher total antioxidant capacity than that of the control group, which suggests that this parameter could be related to the metabolisation of aroma compounds by saliva. Such effects might alter aroma perception in individuals suffering from hyposalivation.

\section{Keywords}

aroma release, metabolisation, saliva, hyposalivation, elderly, total antioxidant capacity 


\section{Practical applications}

The world population is getting older so fast that most countries are not prepared to handle this demographic challenge, characterized by an increasing prevalence of non communicable chronic diseases (e.g. diabetes, gastrointestinal disorders) associated to inadequate eating patterns.

Thus, supporting a balanced diet is one of the most cost-effective strategies to maintain a good quality of life. A suitable diet needs to take into account both, specific sensory and nutritional individual needs. However, ageing is often accompanied by deterioration in oral health (e.g. low salivary secretions), which could alter the capacities to taste and smell. Results from this work contribute to a better understanding of the role of human saliva in aroma release and metabolisation, a first step to comprehend retronasal aroma release and perception. This knowledge will help to propose innovative solutions for the reformulation of food products better adapted to the elderly's needs, thus allowing delayed onset of dependency. 


\section{Introduction}

The interest in the role of human saliva on the food oral processing is growing in last years (Mosca \& Chen, 2017; Muñoz-González, Vandenberghe-Descamps, Feron, Canon, Labouré \& Sulmont-Rossé, 2017; Muñoz-González, Feron \& Canon, 2018; Ployon, Morzel \& Canon, 2017). In several studies, a particular attention is turned to the functions that saliva may play on aroma compounds (Buettner, 2002a; Buettner, 2002b; Genovese, Piombino, Gambuti, \& Moio, 2009; Munoz-Gonzalez, Feron, Brule, \& Canon, 2018; Munoz-Gonzalez, Feron, Guichard, Rodriguez-Bencomo, Martin-Alvarez, Moreno-Arribas, \& Pozo-Bayon, 2014; Pages-Helary, Andriot, Guichard, \& Canon, 2014; Piombino, Genovese, Esposito, Moio, Cutolo, Chambery, Severino, Moneta, Smith, Owens, Gilbert, \& Ercolini, 2014). These studies, carried out ex vivo, have demonstrated that human saliva and its components can increase or decrease the release of aroma compounds via different mechanisms such as noncovalent interactions, salting-out effects or enzymatic conversion. Thus, it is believed that the variability of human saliva might be one of the factors explaining interindividual variation in retronasal aroma release and aroma perception (Feron, Ayed, Qannari, Courcoux, Laboure, \& Guichard, 2014; Guichard, Repoux, Qannari, Laboure, \& Feron, 2017).

However, most of the studies on this topic have employed pooled salivas or individual salivas from a limited number of subjects (Buettner, 2002a; Buettner, 2002b; Genovese et al., 2009; Munoz-Gonzalez et al., 2018; Munoz-Gonzalez et al., 2014; Pages-Helary et al., 2014) that do not represent properly the well-known interindividual variability of human saliva composition in healthy individuals (Leake, Pagni, Falquet, Taroni, \& Greub, 2016; Neyraud, Palicki, Schwartz, Nicklaus, \& Feron, 2012). Additionally, different pathologies or functional states can provoke biochemical and microbiological changes in salivary parameters raising the 
differences in specific populations (Castagnola, Cabras, Vitali, Sanna, \& Messana, 2011; Schipper, Silletti, \& Vinyerhoeds, 2007). This fact leads to hypothesise that people experiencing salivary disorders might present an altered retronasal release and perception of aroma. Hereof, it should be mentioned an original study that showed that saliva from obese people (Body Mass Index (BMI)>30) suppressed aroma release from wine compared to saliva from normal-weight subjects $(18.5<\mathrm{BMI}<24.9)$ (Piombino et al., 2014). Authors observed that saliva from obese individuals $(n=28)$ presented a higher total antioxidant capacity (TAC) compared to that of the controls $(n=28)$. They suggested the induction of a systemic antioxidant response in the saliva from obese subjects, that might have affected the release of aroma compounds in that group.

Elderly people are another specific population affected by salivary disorders. A recent metaanalysis has shown that the ageing process is associated per se with a reduced secretion of the salivary-glands (Affoo, Foley, Garrick, Siqueira, \& Martin, 2015). In the elderlies, such salivary hypofunction could have a negative influence on food consumption as it has been recently reviewed (Muñoz-González, Vandenberghe-Descamps, Feron, Canon, Labouré \& Sulmont-Rossé, 2017). In that article, authors systematically reviewed the existing articles on this topic and they found that most of them showed an association between hyposalivation and a decrease in the chewing and swallowing abilities, but also in taste perception (Iwasaki, Yoshihara, Ito, Sato, Minagawa, Muramatsu, Watanabe, Manz, Ansai, \& Miyazaki, 2016; Samnieng, Ueno, Shinada, Zaitsu, Wright, \& Kawaguchi, 2012; Solemdal, Sandvik, Willumsen, Mowe, \& Hummel, 2012). A relationship between salivary hypofunction and appetite loss (Dormenval, Mojon, \& Budtz-Jorgensen, 1999; Iwasaki et al., 2016) and unbalanced dietary intake was also underlined. However, in spite of the relevance of this 
topic, and the increased of this population group, to the authors' knowledge the effects of saliva on aroma release in elderlies have never been investigated.

For that reason, in this paper the role of interindividual differences of saliva from elderly people on aroma compounds has been studied. Thirty individuals (15 suffering from hyposalivation, 15 with normal salivary flow) were selected from a panel formed by 110 older individuals. Both groups were matched by age and sex. Saliva samples $(n=30)$ were independently incubated in presence of three aroma compounds (ethyl hexanoate, octanal and 2-nonanone). Aroma release was measured by HS-GC. Moreover, LLE-GC/MS analyses were performed to investigate the possible metabolisation of aroma compounds by saliva. Biochemical analyses of the saliva samples were carried out in order to compare the two groups and to understand the relationship between data on saliva composition and the release and metabolisation of aroma compounds.

\section{Material and methods}

\subsection{Aroma compounds}

Three compounds were chosen on the basis of their physicochemical characteristics (similar $\log \mathrm{P}$ and boiling point), their aroma impact, and because of their suitability for the analyses techniques regarding the detection limits and solubility (Table 1). They belong to three chemical families (ketones, aldehydes and esters), known to be affected by saliva (Buettner, 2002a; Buettner, 2002b; Munoz-Gonzalez et al., 2018; Pages-Helary et al., 2014). The aroma compounds were of analytical grade (Aldrich, Steinheim, Germany). A gas chromatographyflame ionization detector (GC-FID) analysis confirmed the purity of all aroma compounds (> 
$98 \%)$, which was take into account for the calculations. Stock solutions (1\%) of single aroma compounds were freshly prepared in propyleneglycol at room temperature under magnetic stirring for $2 \mathrm{~h}$. They were stored at $4{ }^{\circ} \mathrm{C}$ throughout the study, and their stability was periodically checked. The final concentration of the aroma compounds in the water solutions was 3 ppm.

\subsection{Saliva samples}

\subsubsection{Panel of elderly individuals}

A panel of 110 elderly volunteers formed the initial population (AlimaSSenS project: toward an adapted and healthy food supply for elderly people). The AlimaSSens panel was recruited from a population of elderly people living at home in Dijon (France). The recruitment criteria were the following: older than 65 years old, no acute pathological episodes at the time of the experiment, and scoring at least 24 on the mini mental state evaluation, which indicates normal cognition (Folstein, Folstein, \& McHugh, 1975). An interview was carried out with each volunteer to ensure that they met the inclusion criteria. Interested people followed a dentist evaluation and completed a questionnaire asking them about medications and food habits. Exclusionary criteria included any physiological condition or taking medications that could influence salivation (for example antidepressants and antihistamines). Finally, their weight and their height were measured and used to calculate their Body Mass Index (BMI = weight $(\mathrm{kg}) /$ height $\left.^{2}\left(\mathrm{~m}^{2}\right)\right)$. All subjects gave written informed consent to participate in the experiment after receiving oral and written information. The experimental protocol was approved by the French Ethics Committee for Research (CPP Est I, Dijon, \#14.06.03, ANSM \#2014-A00071-46). 


\subsubsection{Saliva collection and salivary flow rates calculation}

Participants were asked not to consume any food or drink at least one hour before saliva was collected. Unstimulated salivary flow was measured by instructing the participants to let the saliva naturally be accumulated in the mouth and then spat it directly into a collection tube during ten minutes. Stimulated salivary flow was measured by instructing the participants to masticate a piece of pre-weighed parafilm while spitting out the saliva into a pre-weighed screw-cap cup every time they felt like swallowing over a period of $5 \mathrm{~min}$. Cups were weighed, and salivary flow rates were expressed in $\mathrm{mL} / \mathrm{min}$ assuming that $1 \mathrm{~g}$ of saliva corresponds to $1 \mathrm{~mL}$. Only stimulated saliva samples were analysed in this study, since this is the saliva secreted during food consumption. Moreover, it has been previously reported that this type of saliva was correlated to aroma release during food consumption (Feron et al., 2014). Saliva samples were alliquoted and stored at $-80^{\circ} \mathrm{C}$ until use.

\subsection{Saliva biochemical analysis}

2.3.1 Protein Concentration. The protein concentration was determined using the Bradford protein assay with bovine serum albumin (BSA) used as the standard for calibration.

2.3.2 Protein profile. Salivary samples were separated by electrophoresis using analytical 4$20 \%$ precast polyacrylamide gels (Biorad, France). The samples (10 $\mu \mathrm{g}$ of total protein content) were diluted into a mixture (v/v) of 2xLaemmli Buffer and Dithiothreitol (100 mM) (final volume $=50 \mu \mathrm{l}$ ). Then, they were heated at $100{ }^{\circ} \mathrm{C}$ during 5 minutes. The gels were performed on a Mini-PROTEAN Tetra Cell (BioRad, France). A control of saliva and a molecular weight marker Precision Plus Protein ${ }^{\mathrm{TM}}$ Unstained (Biorad, France) were loaded in each of the gels. The running buffer 1 X TGS was added into the gels and a separation voltage 
of $200 \mathrm{~V}$ was applied during 40 minutes. After that, the gels were rinsed into the deionized water for 10 minutes. Gel images were acquired on a ChemiDoc ${ }^{\mathrm{TM}} \mathrm{MP}$ imaging system (Biorad, France) for fluorescently stained gels. The time of exposure was 10 seconds. Molecular weight and intensity of each protein band were calculated on the normalized gels by using the ImageLab ${ }^{\text {TM }}$ software (Biorad, France). Spot volumes were normalized within one gel by the total volume of all valid spots for that particular gel and used for statistical analysis.

2.3.3 Total Antioxidant Capacity. The total antioxidant capacity was determined using an ORAC Assay kit (Zen-bio, Research Triangle Park, NC). This assay measures the loss of fluorescein fluorescence over time due to peroxyl radical formation resulting from the breakdown of AAPH (2,2'-azobis-2-methyl-propanimidamide, dihydrochloride). Trolox (6hydroxy-2,5,7,8-tetramethylchroman-2-carboxylic acid), a water soluble vitamin E analogue, serves as a positive control to inhibit fluorescein decay in a dose-dependent manner. The intensity of fluorescence was measured (excitation filter, $485 \mathrm{~nm}$; emission filter, $538 \mathrm{~nm}$ ) using a microtitre plate fluorometer (Victor 3-V, PerkinElmer, France). The total antioxidant capacity was expressed in micromolar Trolox equivalent.

\subsection{Release of aroma compounds by HS-GC}

A previously validated method adapted to microvolumes of saliva was employed (MunozGonzalez et al., 2018). Briefly, three hundred microliters of the aroma solution (containing the three aroma compounds at $3 \mathrm{ppm}$ ) were placed into a $10 \mathrm{~mL}$ headspace vial (Agilent Technologies, Palo Alto, CA, USA). Then, water or stimulated saliva samples $(n=30)$ were added to the vial until a final volume of $500 \mu \mathrm{l}$. Vials were immediately sealed with a PTFE/silicone septum (Supelco, Bellefonte, PA, USA), vortexed and then incubated at $37^{\circ} \mathrm{C}$ during $30 \mathrm{~min}$. After the incubation time, two hundred microliters of headspace were taken 
automatically using a preheated $\left(45^{\circ} \mathrm{C}\right)$ 1-mL gas-tight syringe (Gerstel, manufactured by SGE, Victoria, Australia) and analysed by gas chromatography (Agilent 7890B) in splitless mode at $240{ }^{\circ} \mathrm{C}$. A capillary DW-Wax column $(30 \mathrm{~m}$ x $0.32 \mathrm{~mm}$ i.d x $0.5 \mu \mathrm{m}$; Agilent $\mathrm{J} \& \mathrm{~W}$ Scientific, Folsom, CA, USA) and a flame ionization detector set at $250{ }^{\circ} \mathrm{C}$ were used. The carrier gas was helium at a velocity of $30 \mathrm{~cm}^{3} / \mathrm{s}$. Aroma compounds were analysed at $110^{\circ} \mathrm{C}$ (isothermal temperature). Each salivary sample $(n=30)$ was analysed independently and in triplicate (one injection per sample vial). Salivary samples were analysed in random order.

Linearity and repeatability (calculated in three different days) of the procedure were determined in the mix of the three aroma compounds at five levels of concentration $(0.6,1.2$, 2.5, 5 and $10 \mathrm{mg} / \mathrm{L}$ ), with determination coefficients higher than 0.99 and relative standard deviations lower than $7 \%$ for the three assayed compounds. Absence of interference (competition, interaction...) between the aroma compounds was checked for both water and saliva ( $>>0.05)$. Stability of the aroma compounds and that of the GC system was checked during all the analysis period with no significant differences obtained across days ( $>0.05)$.

\subsection{Recovery of aroma compounds after incubation by LLE-GC/MS}

After incubation at $37^{\circ} \mathrm{C}$ during $30 \mathrm{~min}$, five hundred microliters of a saturated $\mathrm{CaCl}_{2}$ solution were added to the samples to inhibit possible enzymatic reactions (Buettner 2002a, Buettner 2002b). Moreover, samples were acidified with $\mathrm{HCl}$ in order to protonate acids and increase their extraction. The solutions were extracted twice with $1 \mathrm{~mL}$ of dichloromethane (Carlo Erba, Val de Reuil, France) then centrifuged (5000 g, $4{ }^{\circ} \mathrm{C}, 15 \mathrm{~min}$ ) in order to separate the two phases. Prior to the extraction, samples were spiked with $100 \mu$ of the internal standard, methyl nonanoate $(10 \mathrm{mg} / \mathrm{L})$. The combined organic extracts were dried 
over anhydrous $\mathrm{Na}_{2} \mathrm{SO}_{4}$, then concentrated to a total volume of $100 \mu$. Two $\mu 1$ were injected into the GC/MS in splitless mode for $1.5 \mathrm{~min}$ at $240{ }^{\circ} \mathrm{C}$. The oven temperature was programmed to increase from $40(5 \mathrm{~min})$ to $240{ }^{\circ} \mathrm{C}$ at $4{ }^{\circ} \mathrm{C} / \mathrm{min}^{-1}$ and held $5 \mathrm{~min}$. Aroma compounds were separated on a DB-Wax polar capillary column $(30 \mathrm{~m} \times 0.32 \mathrm{~mm}$ i.d. $\times 0.50$ $\mu \mathrm{m}$ film thickness) from Agilent (J\&W Scientific, Folsom, CA, USA). Helium was used as the carrier gas at a flow rate of $1.5 \mathrm{~mL} / \mathrm{min}$. For the MS system (Agilent $5973 \mathrm{~N}$ ), the temperatures of the transfer line, quadrupole, and ion source were 250,150 , and $230{ }^{\circ} \mathrm{C}$, respectively. Electron impact mass spectra were recorded at $70 \mathrm{eV}$ ionization voltages, and the ionization current was $10 \mu \mathrm{A}$. The acquisitions were performed in scan (from 35 to 350 amu) and SIM modes. The identification of compounds was based on the comparison of retention times and mass spectra from three databases: NIST 2.0 and WILEY 138. Relative peak areas (RPAs) were obtained by calculating the relative peak area in relation to that of the internal standard. The use of RPAs data to express aroma release was sufficient for this type of analysis as the aim of the work was to compare the extent of aroma recovery between saliva samples. Each salivary sample $(n=30)$ was analysed independently and in triplicate (one injection per sample vial).

Linearity and repeatability of the procedure were determined in the aqueous solution at four levels of concentration $(0.1,1,5$ and $10 \mathrm{mg} / \mathrm{L})$, with coefficients of determination $\left(\mathrm{R}^{2}\right)$ higher than 0.99 and relative standard deviations lower than $3 \%$ for all the assayed compounds. The same LLE procedure was carried out with the salivas and water samples without added aroma compounds in order to detect any possible compound coming from the salivas or any artefact formed during the extraction procedure. Stability of the aroma compounds and that of the GC/MS was checked in controls during all the analysis period and no significant differences were obtained across days $(\mathrm{p}>0.05)$. 


\subsection{Statistical analyses}

Linear regression analyses were performed to establish the linearity of the response of each aroma compound by GC and GC/MS. Normality test on the two populations (HPS vs control) regarding the SSFR confirmed that both groups were normally distributed. ANOVA analyses and the least significant differences (LSD) test were employed to determine significant differences between the groups. The significance level was $\mathrm{p}<0.05$ throughout the study. The XLstat program was used for data processing (StatSoft, Inc., 2005, www.statsoft.com).

\section{Results and discussion}

\subsection{Description of the panel}

As it can be seen in Table 2, the initial population was formed by 110 persons aged between 65 and $87 \mathrm{y} / \mathrm{o}$ (mean age $=72 \mathrm{y} / \mathrm{o}$ ). Averaged unstimulated salivary flow rate determined for the whole group was $0.31( \pm 0.18)$ and averaged stimulated salivary flow rate was $1.63( \pm 0.82)$ $\mathrm{ml} / \mathrm{min}$.

From this population, 15 individuals presented hyposalivation (measured as the presence of a SSFR lower than $0.8 \mathrm{ml} / \mathrm{min}$ (Soini, Routasalo, Lauri, \& Ainamo, 2003)). Therefore, these 15 individuals formed the hyposalivator group (mean SSFR for the hyposalivator group $=0.61 \pm 0.18 \mathrm{ml} / \mathrm{min})$. The control group was constituted by individuals $(\mathrm{n}=15)$ presenting a SSFR similar to the mean SSFR of the initial population (mean SSFR for the control group $=1.69 \pm 0.17 \mathrm{ml} / \mathrm{min}$ ). Both groups were matched by age and sex. This resulted in 
a higher proportion of women than men in this study. This is because people suffering from hyposalivation in the initial population were mostly women. This gender difference on salivary flow rate has already been described in several articles, and it could be due to the smaller salivary gland size of women comparing to men (Inoue et al., 2006). Table 2 shows that, as expected, the hyposalivator group presented significantly lower unstimulated and stimulated salivary flow rates than the control group. Moreover, the body mass index (BMI) of people forming the hyposalivator group was significantly higher than that of those from the control group (Table 2). An association between high BMI and hyposalivation has already been found by Flink and collaborators (2008). However, the explanations for this association are so far inconclusive. It has been suggested that both parameters could be related to malnutrition, by the appearance of diabetes, cardiovascular diseases, cancer, osteoporosis and caries, or other chronic diseases that might affect both the weight and/or the salivary gland function of the people (Flink, Bergdahl, Tegelberg, Rosenblad, \& Lagerlof, 2008).

\subsection{Aroma release after the interaction of the selected aroma compounds with water or}

\section{with salivas from the hyposalivator and control groups}

Figure 1 shows the aroma release values obtained for each of the three aroma compounds in the water and saliva samples (hyposalivator and control groups) together with the results of the LSD test. As it can be seen, all the assayed compounds were significantly less released in the hyposalivator group compared to the control group and the water samples, although the extent of the effect varied among compounds. Interestingly, octanal was the compound most affected by saliva and the only significantly different between the control group and the water samples. The differences observed among compounds cannot be only explained on the basis of some physicochemical properties of the aroma compounds, such as hydrophobicity or 
boiling point, since these characteristics were similar for the tested molecules (see Table 1). The effect of saliva on aroma compounds varied as a function of their chemical family. The higher effect of human saliva on aldehydes and esters than on monoketones has been previously reported in several publications performed under ex vivo conditions (Buettner, 2002a; Buettner, 2002b; Munoz-Gonzalez et al., 2018; Pages-Helary et al., 2014).

The decrease in the release could be mostly due to two phenomena. On the one hand, aroma compounds might be retained by salivary components (such as proteins), as it has been previously suggested (Pages-Helary et al., 2014). On the other hand, these results could be explained by a transformation of the aroma compounds (Buettner, 2002a; Buettner, 2002b; Munoz-Gonzalez et al., 2018; Pages-Helary et al., 2014) through enzymatic or non-enzymatic reactions by saliva. In any case, the fact that in average, salivas from elderly people suffering from hyposalivation decreased more the release of aroma compounds than saliva from individuals presenting a normal salivary flow could be at the origin of aroma perception anomalies in this population. To the best of the authors' knowledge, this is the first time that this finding has been shown. However, in our study, people from the hyposalivator group presented also a higher BMI compared to those of the control group. In this regard, Piombino and coworkers (Piombino et al., 2014) have already shown that saliva from young obese individuals (high BMI) supresses aroma release compared to saliva from normal-weight subjects. Therefore, in vivo studies controlling for confounding factors (such as BMI) will be needed in order to elucidate the role of hyposalivation on retronasal aroma release and perception.

\subsection{Metabolisation of aroma compounds by salivas from the hyposalivator and control} groups 
The possible metabolisation of the assayed aroma compounds by saliva was investigated by LLE-GC/MS. After incubating the aroma compounds in the presence of each of the 30 saliva samples or water during $30 \mathrm{~min}$ at $37{ }^{\circ} \mathrm{C}$, aroma compounds were extracted with dichloromethane and analysed by GC-MS. Blanks of saliva without the aroma compounds or the aroma compounds without saliva were also analysed in the same conditions.

A one-way ANOVA analysis was performed on the extracted amounts of octanal, ethyl hexanoate, 2-nonanone after their incubation in the presence of the 30 saliva samples or water. These results are shown in Table 3. As it can be observed, the three assayed compounds presented a significantly lower recovered quantity of the three aroma compounds in the saliva samples from the hyposalivator group compared to the water samples and to the salivas from the control group. In agreement with the aroma release analyses, octanal was the only compound significantly different between the control group and the water samples. Table 3 also shows that the recovered quantity of the three aroma compounds was significantly lower in the salivas from the hyposalivator group compared to those of the control group. Assuming the fact that the addition of the solvent to the samples would loss the integrity of salivary proteins, non-covalent interactions between protein and aroma compounds are unlikely to survive to the solvent changes. Therefore, they are unlikely to explain the different recovery between the two groups. Therefore, a stronger metabolisation of the three compounds in the hyposalivator group compared to the control group is the most plausible mechanism to explain our results, despite that the involvement of non-covalent interactions cannot be excluded. 
Additionally, the presence of metabolites was checked in order to investigate which type of conversion suffered the aroma compounds by saliva. The type of reaction was clearly confirmed for octanal that was reducted to 1-octanol (Figure 2). In agreement, no octanol was found in the water samples and a significant lower production of 1-octanol was obtained in the control group compared to the hyposalivator group (Table 3). In the case of ethyl hexanoate, its expected metabolite (the hexanoic acid) was also detected in the blanks of saliva without aroma compounds added (Figure 2). Therefore, its formation by the effect of salivary components could not be definitely proven in the present study. Finally, no metabolite was detected for the 2-nonanone (Figure 2), which was possibly due to a limitation on the sensibility of our method.

Overall, these findings confirm a different metabolisation rate of aroma compounds in the two salivary groups. Therefore, these results suggest that elderly people suffering from hyposalivation could present an altered aroma perception (e.g. due to a lower availability of aroma compounds to reach the olfactory receptors retronasally and/or to a higher formation of new aroma compounds (i.e. metabolites) which might present different odor thresholds and qualities). This relevant finding needs to be verified in vivo.

\subsection{Researching the origin of the differences observed on aroma release and metabolism between the hyposalivator and the control groups}

In a previous study performed with artificial or pooled human saliva, it has been suggested that salivary proteins such as mucin and alpha-amylase could interact with aroma compounds, affecting their release to the headspace (Pages-Helary et al., 2014). In another work, Piombino and coworkers (Piombino et al., 2014) showed that saliva from obese individuals 
presented a significantly higher total antioxidant capacity and lower ex vivo aroma release than saliva from normal-weight subjects. In agreement with those papers, Munoz-Gonzalez et al., (2018) observed that the highest the total protein content and the total antioxidant capacity of the saliva samples, the lowest the ex vivo aroma release. However, the latter study was performed with a limited number of saliva samples $(n=3)$. Consequently, the protein content and the total antioxidant seem to be two factors affecting the behaviour of aroma compounds in presence of saliva. To validate this hypothesis, these parameters were analysed in the 30 saliva samples selected for this study and results are shown bellow.

\subsubsection{Total Protein Content (TPC) and protein profile of saliva from hyposalivators or control subjects}

As it can be seen in Figure 3, the TPC values between the hyposalivator and control groups were not significantly different $(\mathrm{p}=0.710)$. Therefore, this parameter did not seem to be enough to explain the differences in the aroma release and metabolisation observed in the two salivary groups of the present study. These differences could be more likely due to specific non-covalent interactions or enzymatic reactions. In this regard, Pages-Helary et al. (2014) suggested that specific salivary proteins such as mucin and alpha-amylase affect the release of esters and monoketones. Consequently, we further explored the protein profile of the 30 saliva samples through electrophoresis in order to know if the relative amount of specific proteins could better explain the aroma release and metabolisation data. One example of the protein profiles obtained is shown in Figure 4. From that analysis, seven spots were identified in more than the $80 \%$ of the saliva samples and their relative abundances determined. However, the determination of mucins could not be possible due to the high molecular weight of these proteins and no significant differences were observed between groups in the band 
corresponding to the protein alpha-amylase between groups $(55 \mathrm{kDa})$. This could be due to the fact that different proteins could have comigrated in the same band of the gel, which could have masked the differences of specific proteins between groups. Interestingly, three bands, in the range of $10-15 \mathrm{kDa}$, were significantly different between the two salivary groups $(\mathrm{p}<0.1)$. Consequently, these preliminary results open the door to new proteomics studies in order to identify the protein(s) involved in the observed results.

\subsubsection{Total Antioxidant Capacity (TAC) of saliva from hyposalivators or control subjects}

To check a possible role of TAC on the differences on aroma release and metabolism observed in the two groups, TAC was analysed in the 30 saliva samples and results showed significant differences in the TAC values between both groups (Figure 5). In this regard, the hyposalivator group presented significantly higher TAC values than those of the control group, which might explain at least partially the higher metabolisation rate and thus, the lower aroma release observed for this group. In previous papers, it has been suggested a negative association between the salivary TAC and the ex vivo release of aroma compounds (MunozGonzalez et al., 2018; Piombino et al., 2014). Although the mechanisms on how TAC impact aroma release are to date unclear, these effects could be related to the oxidative status of the saliva samples, which could affect the aroma compounds prone to redox reactions (Piombino et al., 2014). Recently, it was ascertained that the presence of NADH helped to take place at a higher rate the enzymatic conversion of aroma compounds (octanal) by saliva (MunozGonzalez et al., 2018). NADH is a coenzyme, which is used as a reducing agent. Moreover, it has been suggested a relation between the antioxidant status and the total amount of reducing agents in saliva (Kohen, Tirosh, \& Kopolovich, 1992). Therefore, it is possible that people 
with high TAC have also high concentration of NADH in their saliva. However, further research is required to validate this hypothesis.

Finally, it should be mentioned that the effects of hyposalivation on aroma compounds need to be validated in vivo, taking into account the control of confounding factors (age, gender, BMI, drug intake, diseases, mental status or dental status). As stated above, salivary parameters might be modified by the health status of individuals. For example, it has been seen that obese people presented higher TAC values than normal-weight subjects (Piombino et al., 2014) and that patients with dementia presented lower TAC values than control subjects (Choromanska, Klimiuk, Kostecka-Sochon, Wilczynska, Kwiatkowski, Okuniewska, Waszkiewicz, Zalewska, \& Maciejczyk, 2017). Moreover, hyposalivation is frequently present in diverse systemic diseases and immunological disorders, such as obesity (Flink, Bergdahl, Tegelberg, Rosenblad, \& Lagerlof, 2008), diabetes mellitus (Conner, Iranpour, \& Mills, 1970) or dementia (e.g. Alzheimer's dementia) (Choromanska et al., 2017; Flink et al., 2008), and it can be also an adverse effect of the treatments (such as radiotherapy) employed to treat them (Narhi, Meurman, Ainamo, Nevalainen, Schmidtkaunisaho, Siukosaari, Valvanne, Erkinjuntti, Tilvis, \& Makila, 1992; Schubert \& Izutsu, 1987; Sreebny \& Valdini, 1988; Valdez, Atkinson, Ship, \& Fox, 1993). Therefore, as hyposalivation might have different origins, the dispersion of saliva composition of the subjects suffering it (and therefore its effect on aroma perception) could also be very high. Moreover, some of these conditions (e.g. dementia) could affect directly the sensory integration in the brain, masking the contribution of saliva to aroma perception.

\section{Conclusions}


In conclusion, from a panel formed by 110 elderly people, 15 of them suffered from hyposalivation (measured as presenting a salivary flow rate lower than $0.8 \mathrm{ml} / \mathrm{min}$ ), which represented the $13.6 \%$ of the population. Most of them were women.

Moreover, this work has demonstrated for the first time that interindividual differences of saliva from elderly people affect aroma release and ex vivo metabolisation of aroma compounds. In particular, saliva from elderly people suffering from hyposalivation presented a lower release and/or a higher metabolisation of aroma compounds (octanal, ethyl hexanoate and 2-nonanone) than saliva from the control group. Although no differences on the total protein content between groups were found, the involvement of specific proteins on the present results cannot be discarded. Moreover, saliva from the hyposalivator group presented a significantly higher TAC mean than that of the control group.

These findings could indicate that people suffering from hyposalivation could present an altered aroma perception due to a different amount of aroma compounds reaching the olfactory receptors by the retronasal pathway, concomitantly with the dissimilar formation of new metabolites with different sensory properties. However, this finding found under ex vivo conditions will need to be confirmed in an in vivo and more realistic situation, in which the influence of other orophysiological parameters can be taken into account and in times comparable with the eating process. Moreover, the control of confounding factors in future research is mandatory to assess if these differences among salivary groups observed ex vivo can have a sensory meaning.

\section{Financial support}

This work has been performed with the support of i) the Agreenskills fellowship programme 
which has received funding from the EU's Seventh Framework Programme under grant agreement $\mathrm{N}^{\circ} \mathrm{FP} 7-609398$ (AgreenSkills+ contract), ii) the research prize awarded by the French Nutrition Society in 2017 to C.M-G and iii) the projects: MUFFIN N ${ }^{\circ} 14-C E 20-0001-$ 01 and AlimaSSenS Nº14-CE20-0003-01.

\section{Ethical statements}

\section{Conflict of interest}

The authors declare no conflict of interest in publishing this work.

\section{Ethical review}

This study was approved by the French Ethics Committee for Research (CPP Est I, Dijon, \#14.06.03, ANSM \#2014-A00071-46).

\section{Informed consent}

Written informed consent was obtained from all study participants.

\section{Acknowledgements}

We give a special thank you to Chantal Septier and Aurelie Prot for technical assistance and to the volunteers for providing us the saliva samples.

\section{References}

Affoo, R. H., Foley, N., Garrick, R., Siqueira, W. L., \& Martin, R. E. (2015). Meta-Analysis of Salivary Flow Rates in Young and Older Adults. Journal of the American Geriatrics Society, 63(10), 2142-2151. doi:10.1111/jgs.13652

Buettner, A. (2002a). Influence of human saliva on odorant concentrations. 2. aldehydes, alcohols, 3-alkyl-2-methoxypyrazines, methoxyphenols, and 3-hydroxy-4,5-dimethyl2(5H)-furanone. Journal of Agricultural and Food Chemistry, 50(24), 7105-7110. doi:10.1021/jf020714o

Buettner, A. (2002b). Influence of human salivary enzymes on odorant concentration changes occurring in vivo. 1. Esters and thiols. Journal of Agricultural and Food Chemistry, 50(11), 3283-3289. doi:10.1021/jf011586r

Castagnola, M., Cabras, T., Vitali, A., Sanna, M. T., \& Messana, I. (2011). Biotechnological implications of the salivary proteome. Trends in Biotechnology, 29(8), 409-418. doi:10.1016/j.tibtech.2011.04.002 
Choromanska, M., Klimiuk, A., Kostecka-Sochon, P., Wilczynska, K., Kwiatkowski, M., Okuniewska, N., et al. (2017). Antioxidant Defence, Oxidative Stress and Oxidative Damage in Saliva, Plasma and Erythrocytes of Dementia Patients. Can Salivary AGE be a Marker of Dementia? International Journal of Molecular Sciences, 18(10). doi:10.3390/ijms18102205

Conner, S., Iranpour, B., \& Mills, J. (1970). alteration in parotid salivary flow in diabetes mellitus. Oral Surgery Oral Medicine Oral Pathology Oral Radiology and Endodontics, 30(1), 55-\&. doi:10.1016/0030-4220(70)90011-3

Dormenval, V., Mojon, P., \& Budtz-Jorgensen, E. (1999). Associations between self-assessed masticatory ability, nutritional status, prosthetic status and salivary flow rate in hospitalized elders. Oral Dis, 5(1), 32-38.

Feron, G., Ayed, C., Qannari, E. M., Courcoux, P., Laboure, H., \& Guichard, E. (2014). Understanding Aroma Release from Model Cheeses by a Statistical Multiblock Approach on Oral Processing. Plos One, 9(4). doi:10.1371/journal.pone.0093113

Flink, H., Bergdahl, M., Tegelberg, A., Rosenblad, A., \& Lagerlof, F. (2008). Prevalence of hyposalivation in relation to general health, body mass index and remaining teeth in different age groups of adults. Community Dentistry and Oral Epidemiology, 36(6), 523-531. doi:10.1111/j.1600-0528.2008.00440.x

folstein, m. f., folstein, s. e., \& mchugh, p. r. (1975). Mini-mental state - practical method for grading cognitive state of patients for clinician. Journal of Psychiatric Research, 12(3), 189-198. doi:10.1016/0022-3956(75)90026-6

Genovese, A., Piombino, P., Gambuti, A., \& Moio, L. (2009). Simulation of retronasal aroma of white and red wine in a model mouth system. Investigating the influence of saliva on volatile compound concentrations. Food Chemistry, 114(1), 100-107. doi:10.1016/j.foodchem.2008.09.022

Guichard, E., Repoux, M., Qannari, E. M., Laboure, H., \& Feron, G. (2017). Model cheese aroma perception is explained not only by in vivo aroma release but also by salivary composition and oral processing parameters. Food \& Function, 8(2), 615-628. doi:10.1039/c6fo01472k

Inoue, H., Ono, K., Masuda, W., Morimoto, Y., Tanaka, T., Yokota, M., et al. (2006). Gender difference in unstimulated whole saliva flow rate and salivary gland sizes. Archives of Oral Biology, 51(12), 1055-1060. doi:10.1016/j.archoralbio.2006.06.010

Iwasaki, M., Yoshihara, A., Ito, K., Sato, M., Minagawa, K., Muramatsu, K., et al. (2016). Hyposalivation and dietary nutrient intake among community-based older Japanese. Geriatr Gerontol Int, 16(4), 500-507. doi:10.1111/ggi.12500

Kohen, R., Tirosh, O., \& Kopolovich, K. (1992). The reductive capacity index of saliva obtained from donors of various ages. Experimental Gerontology, 27(2), 161-168. doi:10.1016/0531-5565(92)90040-7

Leake, S. L., Pagni, M., Falquet, L., Taroni, F., \& Greub, G. (2016). The salivary microbiome for differentiating individuals: proof of principle. Microbes and Infection, 18(6), 399405. doi:10.1016/j.micinf.2016.03.011

Mosca, A. C., \& Chen, J. S. (2017). Food-saliva interactions: Mechanisms and implications. Trends in Food Science \& Technology, 66, 125-134. doi:10.1016/j.tifs.2017.06.005

Muñoz-González, C; Feron, G; Canon, F. (2018). Main effects of human saliva on flavour perception and the potential contribution to food consumption. Proceedings of the Nutrition Society. doi:https://doi.org/10.1017/S0029665118000113

Munoz-Gonzalez, C., Feron, G., Brule, M., \& Canon, F. (2018). Understanding the release and metabolism of aroma compounds using micro-volume saliva samples by ex vivo approaches. Food Chemistry, 240, 275-285. doi:10.1016/j.foodchem.2017.07.060 
Munoz-Gonzalez, C., Feron, G., Guichard, E., Rodriguez-Bencomo, J. J., Martin-Alvarez, P. J., Moreno-Arribas, M. V., et al. (2014). Understanding the Role of Saliva in Aroma Release from Wine by Using Static and Dynamic Headspace Conditions. Journal of Agricultural and Food Chemistry, 62(33), 8274-8288. doi:10.1021/jf503503b

Muñoz-González, C., Vandenberghe-Descamps, M., Feron, G., Canon, F., Labouré, H., Sulmont-Rossé, C. (2017). Association between salivary hypofunction and food consumption in the elderlies. A systematic literature review. J Nutr Health Aging. doi:https://doi.org/10.1007/s12603-017-0960-X

Narhi, T. O., Meurman, J. H., Ainamo, A., Nevalainen, J. M., Schmidtkaunisaho, K. G., Siukosaari, P., et al. (1992). Association between salivary flow-rate and the use of systemic medication among 76-year-old, 81-year-old, and 86-year-old inhabitants in helsinki, finland. Journal of Dental Research, 71(12), 1875-1880. doi:10.1177/00220345920710120401

Neyraud, E., Palicki, O., Schwartz, C., Nicklaus, S., \& Feron, G. (2012). Variability of human saliva composition: Possible relationships with fat perception and liking. Archives of Oral Biology, 57(5), 556-566. doi:10.1016/j.archoralbio.2011.09.016

Pages-Helary, S., Andriot, I., Guichard, E., \& Canon, F. (2014). Retention effect of human saliva on aroma release and respective contribution of salivary mucin and alphaamylase. Food Research International, 64, 424-431. doi:10.1016/j.foodres.2014.07.013

Piombino, P., Genovese, A., Esposito, S., Moio, L., Cutolo, P. P., Chambery, A., et al. (2014). Saliva from Obese Individuals Suppresses the Release of Aroma Compounds from Wine. Plos One, 9(1). doi:10.1371/journal.pone.0085611

Ployon, S., Morzel, M., \& Canon, F. . (2017). The role of saliva in aroma release and perception. Food Chem, 226, 212-220.

Samnieng, P., Ueno, M., Shinada, K., Zaitsu, T., Wright, F. A. C., \& Kawaguchi, Y. (2012). Association of hyposalivation with oral function, nutrition and oral health in community-dwelling elderly Thai. Community Dent Health, 29(1), 117-123. doi:10.1922/CDH_2690Ueno07

Schipper, R. G., Silletti, E., \& Vinyerhoeds, M. H. (2007). Saliva as research material: Biochemical, physicochemlical and practical aspects. Archives of Oral Biology, 52(12), 1114-1135. doi:10.1016/j.archoralbio.2007.06.009

Schubert, M. M., \& Izutsu, K. T. (1987). Iatrogenic causes of salivary-gland dysfunction. Journal of Dental Research, 66, 680-688. doi:10.1177/00220345870660s213

Soini, H., Routasalo, P., Lauri, S., \& Ainamo, A. (2003). Oral and nutritional status in frail elderly. Spec Care Dentist, 23(6), 209-215.

Solemdal, K., Sandvik, L., Willumsen, T., Mowe, M., \& Hummel, T. (2012). The Impact of Oral Health on Taste Ability in Acutely Hospitalized Elderly. PLoS One, 7(5). doi:10.1371/journal.pone.0036557

Sreebny, L. M., \& Valdini, A. (1988). Xerostomia .1. relationship to other oral symptoms and salivary-gland hypofunction. Oral Surgery Oral Medicine Oral Pathology Oral Radiology and Endodontics, 66(4), 451-458. doi:10.1016/0030-4220(88)90268-X

Valdez, I. H., Atkinson, J. C., Ship, J. A., \& Fox, P. C. (1993). Major salivary-gland function in patients with radiation-induced xerostomia - flow-rates and sialochemistry. International Journal of Radiation Oncology Biology Physics, 25(1), 41-47. doi:10.1016/0360-3016(93)90143-j 


\section{FIGURE CAPTIONS :}

Figure 1. Aroma release values obtained after the incubation of the three aroma compounds at $37^{\circ} \mathrm{C}$ during $30 \mathrm{~min}$ with water or with salivas $(\mathrm{n}=30)$ from the hyposalivator (HPS) or control groups and analysed by HS-GC. Different letters across the different groups denote statistical differences after application of the LSD test.

Figure 2. Chromatograms corresponding to one saliva sample incubated with water or the same saliva incubated with the aroma compounds selected for this study. Numbers in the chromatogram correspond to the compounds: 1. ethyl hexanoate, 2. octanal, 3. 2-nonanone, 4. methyl nonanoate (IS), 5. octanol and 6. hexanoic acid.

Figure 3. Box plot representation of the Total Protein Content (TPC) determined in the salivas from the hyposalivator and control groups. Box outline represents lower and upper quartiles, the line inside the box is the median value and the circles correspond to the smallest and largest observations.

Figure 4. Protein profiles corresponding to the protein standard (1) and the stimulated salivary samples from two subjects: one hyposalivator (2) and one control (3).

Figure 5. Box plot representation of the Total Antioxidant Capacity (TAC) determined in the salivas from the hyposalivator and control groups. Box outline represents lower and upper quartiles, the line inside the box is the median value and the arms of the box correspond to the smallest and largest observations. (*** significant differences $\mathrm{p}<0.0001)$. 


\section{TABLES :}

Table 1. Physicochemical properties of the aroma compounds employed in this study.

\begin{tabular}{ccccccccc}
\hline $\begin{array}{c}\text { Aroma } \\
\text { compounds }\end{array}$ & $\begin{array}{c}\text { CAS } \\
\text { Number }\end{array}$ & $\begin{array}{c}\text { Chemical } \\
\text { family }\end{array}$ & $\begin{array}{c}\text { Chemical } \\
\text { formula }\end{array}$ & $\begin{array}{c}\mathbf{M W}^{\mathrm{a}} \\
(\mathbf{g} / \mathbf{m o l})\end{array}$ & $\begin{array}{c}\mathbf{l o g} \\
\mathbf{P}^{\mathbf{b}}\end{array}$ & $\begin{array}{c}\mathbf{B P}^{\mathbf{c}} \\
\left({ }^{\circ} \mathbf{C}\right)\end{array}$ & $\begin{array}{c}\text { Solubility }^{\mathbf{d}} \\
(\mathbf{m g} / \mathbf{L})\end{array}$ & Aroma descriptor $^{\mathrm{e}}$ \\
$\begin{array}{c}\text { Ethyl } \\
\text { hexanoate }\end{array}$ & $123-66-0$ & Ester & $\mathrm{C}_{8} \mathrm{H}_{16} \mathrm{O}_{2}$ & 144 & 2.8 & 168 & 308 & fruity \\
Octanal & $124-13-0$ & Aldehyde & $\mathrm{C}_{8} \mathrm{H}_{16} \mathrm{O}$ & 128 & 2.8 & 176 & 394 & fat, lemon, green \\
2-nonanone & $821-55-6$ & Ketone & $\mathrm{C}_{9} \mathrm{H}_{18} \mathrm{O}$ & 142 & 2.7 & 185 & 171 & blue cheese, fatty, fruity \\
\hline
\end{tabular}

${ }^{a}$ Molecular weight

${ }^{\mathrm{b}}$ Hydrophobic constant estimated using molecular modeling software EPI Suite (U.S. EPA 2000-2007)

${ }^{c}$ Boiling point estimated using molecular modeling software EPI Suite (U.S. EPA 2000-2007)

${ }^{\mathrm{d}}$ Solubility in water estimated using molecular software EPI Suite (U.S. EPA 2000-2007)

${ }^{\mathrm{e}}$ From Flavornet database (http://www.flavornet.org; accessed October 2009) 
Table 2. Description of the elderly panel

\begin{tabular}{|c|c|c|c|c|}
\hline & Initial population & Hyposalivator group & Control group & $p$-value \\
\hline Number of subjects & 110 & 15 & 15 & \\
\hline Sex (male; female) & $51 ; 59$ & $3 ; 12$ & $3 ; 12$ & \\
\hline Mean age $( \pm S D)$ & $71.6( \pm 5.5)$ & $72.3( \pm 5.6)$ & $71.4( \pm 4.3)$ & \\
\hline Mean BMI* $\left(\mathrm{kg} / \mathrm{m}^{2}\right)$ & $27.4( \pm 4.3)$ & $28.6( \pm 5.1)^{\mathrm{a}}$ & $25.2( \pm 3.9)^{b}$ & $p=0.0500$ \\
\hline USFR** $(\min ; \max )(\mathrm{ml} / \mathrm{min})$ & $0.05 ; 0.90$ & $0.05 ; 0.41$ & $0.16 ; 0.51$ & \\
\hline Mean USFR (ml/min) & $0.31( \pm 0.18)$ & $0.15( \pm 0.10)^{b}$ & $0.32( \pm 0.11)^{\mathrm{a}}$ & $p=0.0002$ \\
\hline SSFR (min; max) (ml/min) & $0.23 ; 4.55$ & $0.23 ; 0.80$ & $1.35 ; 1.93$ & \\
\hline Mean SSFR $* * *(m l / m i n)$ & $1.63( \pm 0.82)$ & $0.61( \pm 0.18)^{b}$ & $1.69( \pm 0.17)^{\mathrm{a}}$ & $p \unlhd 0.0001$ \\
\hline
\end{tabular}

* Body Mass Index (BMI, $\mathrm{Kg} / \mathrm{m}^{2}$ )

** USFR: Unstimulated Salivary Flow Rate

*** SSFR: Stimulated Salivary Flow Rate

In bold, statistical differences between the hyposalivator and control groups. Different letters across the different groups denotes statistical differences after the application of the LSD test. 

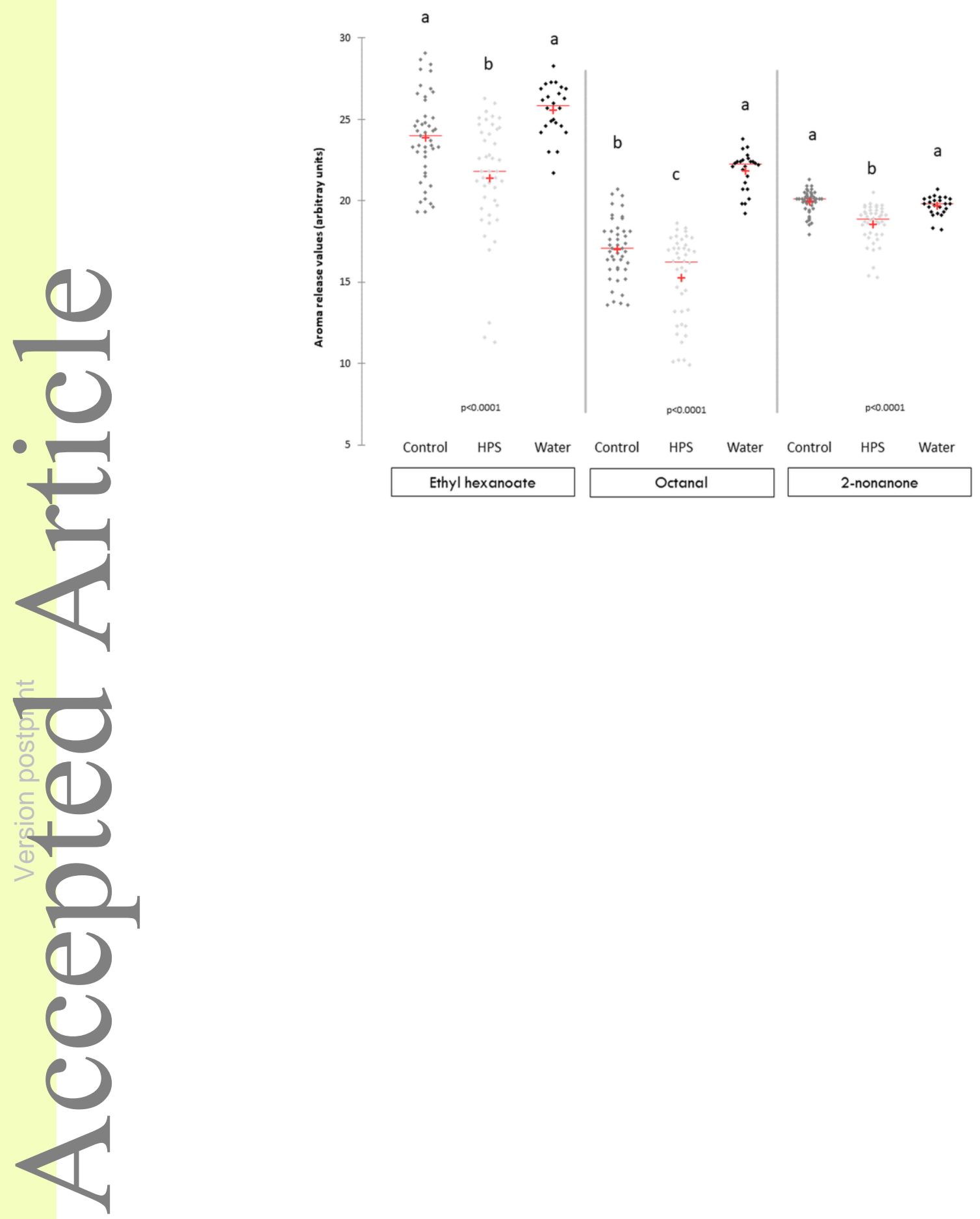

Muñoz González, C. (Auteur de This article is protected by copyright. All rights reserved. Does interindividual variability of saliva affect the release and metabolisation of aroma compounds ex-vivo? The particular case of elderly suffering or not from hyposalivation. Journal of Texture 


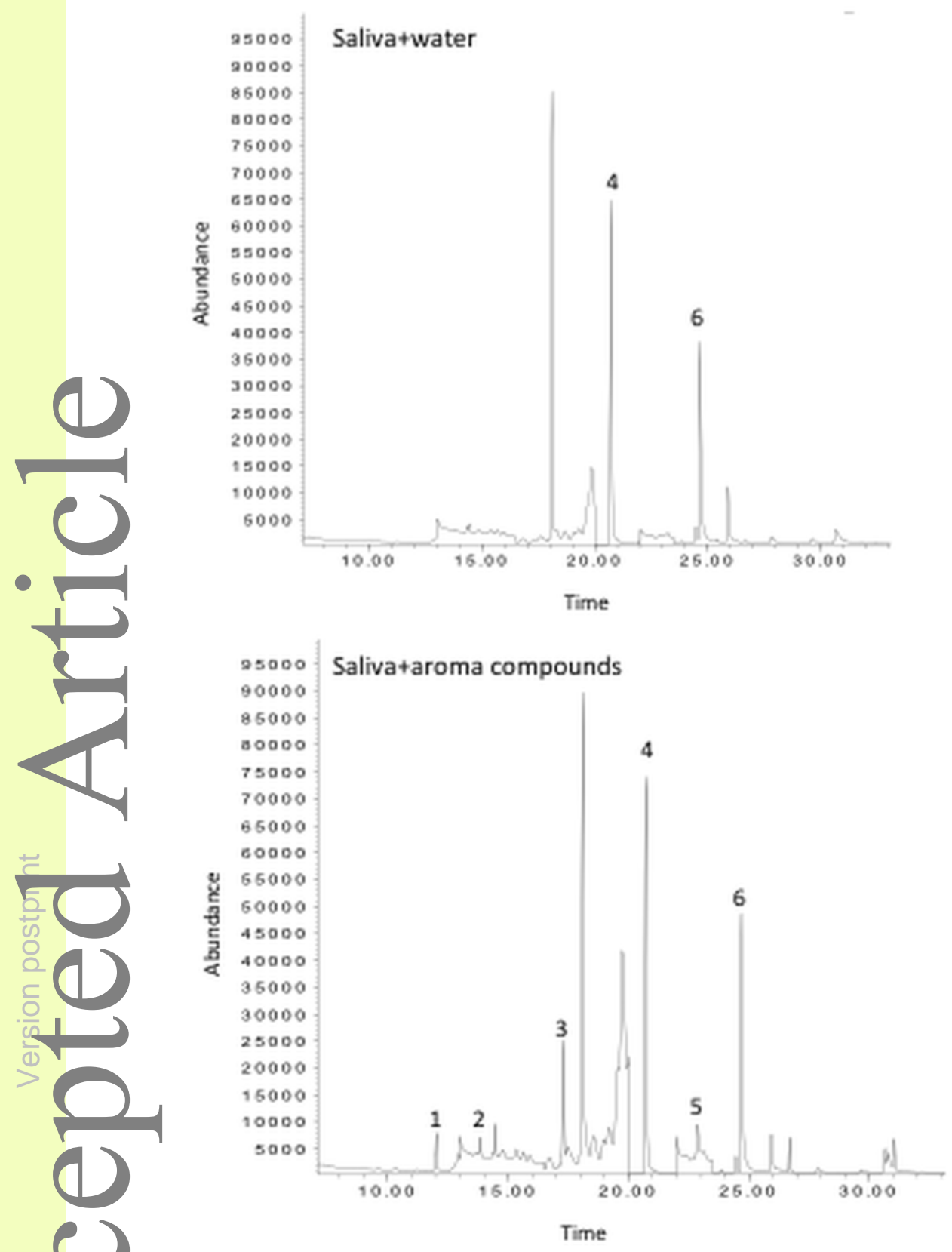



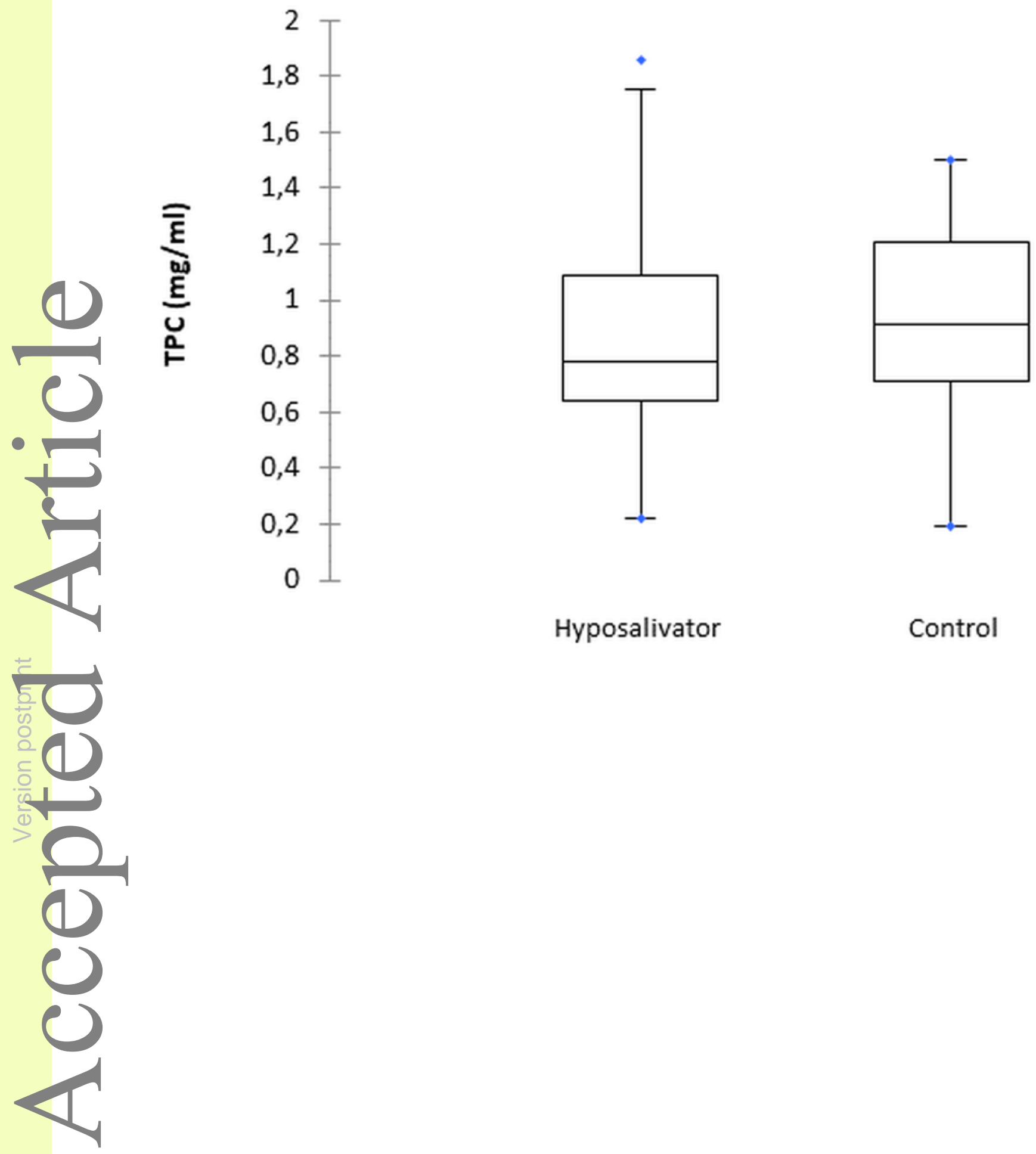

Hyposalivator

Control 


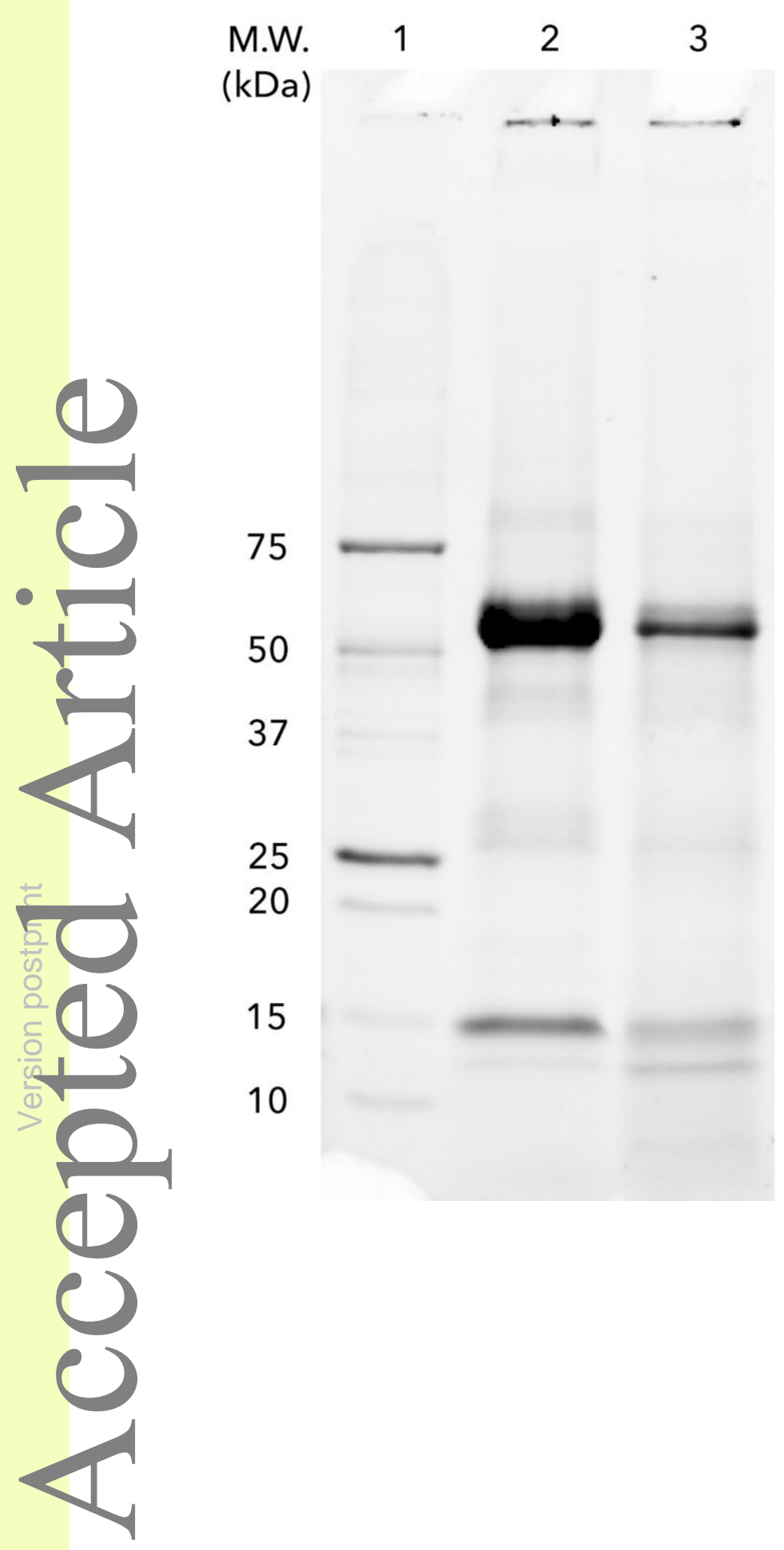

This article is protected by copyright. All rights reserved. Does 


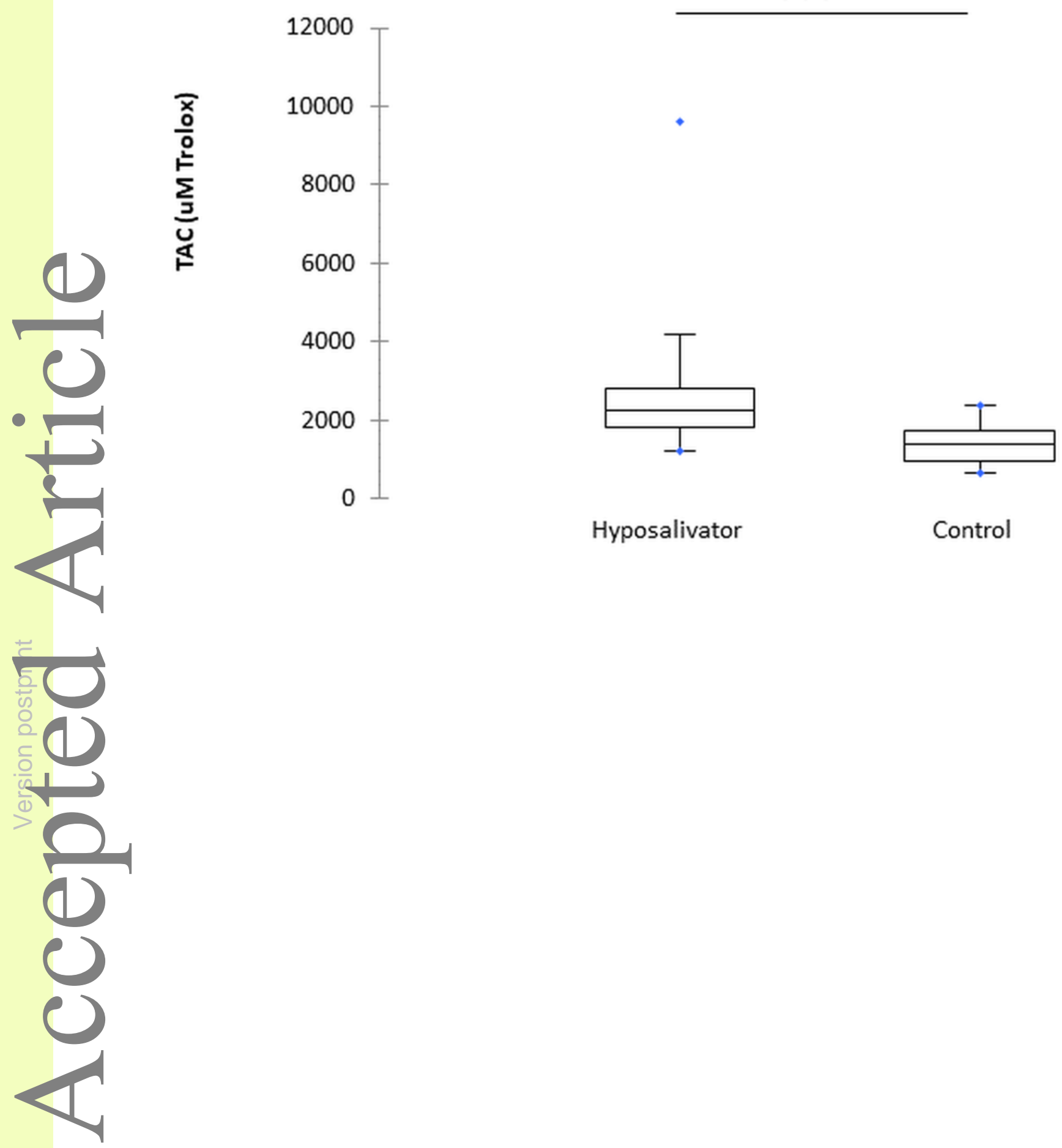

